\title{
A neoruralidade em Araguari-MG frente às políticas públicas voltadas ao desenvolvimento rural no brasil
}

\author{
La neoruralidad en Araguari-MG frente las políticas públicas volver al desarrollo rural \\ en Brasil
}

DOI: $10.5935 / 2447-8539.20190009$

\author{
César Antônio de Oliveira \\ e-mail:cesar.caoli@gmail.com
}

\begin{abstract}
Resumo
A economia brasileira se modernizou bastante durante o século $X X$, principalmente na sua segunda metade, mas esta modernização, na maioria das vezes reativa aos ditames do capitalismo mundial, trouxe uma série de sequelas de caráter socioeconômico que intensificaram as disparidades regionais, setoriais e sociais. A opção pela industrialização como ideal de desenvolvimento econômico relevou as atividades produtivas rurais a, no mínimo, um segundo plano, estabelecendo-se, então, um amplo embate entre o industrial-urbano-moderno e o agrícola-rural-arcaico. Todavia, quando, no seu circuito de acumulação, o capital necessitou da exploração do rural, implementou-se muitas políticas públicas que traziam no seu conceito o desenvolvimento rural no Brasil. Estas políticas, na verdade e na prática, nada mais fizeram do que reproduzir no setor rural os mesmos mecanismos de exploração do capitalismo industrial, com intensa incorporação de capital à produção agrícola, desestabilizando as atividades de agricultura de pequeno porte, voltadas à subsistência familiar ou aos mercados regionais e locais. Criou-se um paradigma de ruralidade, neste ensaio denominado de neoruralidade, atrelado aos preceitos da reprodução capitalista moderna no setor agrícola, basicamente vinculado ao chamado agronegócio.
\end{abstract}

Palavras-chave: Modernidade agrícola. Desenvolvimento rural. Ruralidade.

\section{Resumen}

La economía brasileña se modernizó bastante durante el siglo XX, principalmente en su segunda mitad, pero esta modernización, la mayoría de las veces reactiva a los dictámenes del capitalismo mundial, trajo una serie de secuelas de carácter socioeconómico que intensificaron las disparidades regionales, sectoriales y sociales. La opción por la industrialización como ideal de desarrollo económico relevó las actividades productivas rurales a, como mínimo, un segundo plano, estableciéndose entonces un amplio embate entre lo industrial-urbano-moderno y el agrícola-rural-arcaico. Sin embargo, cuando, en su circuito de acumulación, el capital necesitó la explotación del rural, se implementó un gran número de políticas públicas que traían en su concepto el desarrollo rural en Brasil. Estas políticas, en realidad y en la práctica, nada más hicieron que reproducir en el sector rural los mismos mecanismos de explotación del capitalismo industrial, con intensa incorporación de capital a la producción agrícola, desestabilizando las actividades de agricultura de pequeño porte, volcadas a la subsistencia familiar o a los mercados regionales y locales. Se creó un nuevo paradigma de ruralidad, en este ensayo denominado de neoruralidad, atado a los preceptos de la reproducción capitalista moderna en el sector agrícola, básicamente vinculado al llamado agronegocio.

Keywords: $\quad$ Modernidad agrícola. Desarrollo rural. Ruralidad. 


\section{INTRODUÇÃO}

Em ampla literatura disponível, algumas utilizadas como referências neste ensaio e várias outras obras, tem-se que as discussões temáticas referentes ao desenvolvimento rural no Brasil tendem a ser perenes, mesmo após o incremento de inúmeras políticas públicas para a agricultura cujo foco principal, pelo menos em seus textos, quando de suas elaborações, versa sobre medidas que visam diminuir as desigualdades setoriais, regionais e sociais entre o urbano e o rural.

Há cerca de duas décadas, no texto "O novo rural brasileiro", Graziano da Silva (1997) já descrevia, discutia e analisava, de forma bastante elucidativa e didática, os efeitos provocados pelo padrão capitalista de produção incorporado, de forma massiva, no setor agrícola brasileiro, principalmente a partir da década de 1970.

Enquanto instrumento capaz de promover mudanças significativas em cenários de (re)produção econômica, este padrão, desde sempre, (re)articula as relações sociais entre o trabalho e o capital, e promove um processo contínuo de desequilíbrios entre as atividades consideradas urbanas e as rurais. 0 autor inicia o texto com a frase: "Está cada vez mais difícil delimitar o que é rural e o que é urbano". (GRAZIANO DA SILVA, 1997, p. 01)

De forma bastante similar, Veiga (2001, P. 11) sinaliza que, "é muito importante entender, então, que no capitalismo mais avançado o desenvolvimento de uma região rural há muito tempo deixou de depender do desempenho de sua agricultura".

No âmbito deste ensaio, passou-se a adotar o termo "neoruralidade" como aquele que talvez possa caracterizar o atual padrão das relações sociais de produção no cenário agrícola no Brasil, enxertado por inúmeros elementos da "cultura urbana" e que trazem, em si, um quê de modernidade.

Para Medeiros (2017, p. 180), "o discurso do moderno está, portanto, presente no cotidiano dos agriculatores e se instalou nos lugares absorvidos pela modernização."

No texto de Graziano da Silva (1997) há uma série de apontamentos cuja intencionalidade é a caracterização do deste novo rural brasileiro, frente à chamada "modernização da agricultura" e aos ditames do ritmo do capital na lógica da "globalização" econômica, que levaram a uma intensa alteração de elementos que, anteriormente, poderiam ser os diferenciadores do espaço urbano e do rural.

No entanto, deve-se tomar bastante cuidado ao se estabelecer generalizações, pois mesmo sendo visível e latente a incorporação do cenário rural à cadeia de produção dita capitalista, há que lembrar que o conceito de ruralidade não é apenas de cunho econômico, versando também sobre aspectos sociais, culturais e, em muitos casos, psicológicos.

Ainda em Medeiros (2017), tem-se que:

[...] o conceito de ruralidade se define tanto no plano sociológico como no geográfico e, é definido originalmente como um espaço habitado por pequenas comunidades humanas, com valores mútuos e história comum que giram ainda em torno da fidelidade e do pertencimento a um meio, a um território e a família. Ali se reencontra uma dinâmica distinta e práticas sociais, culturais e econômicas fundadas sobre a proximidade, a convivialidade, a ajuda e a cooperação. (MEDEIROS, 2017, p. 181)

A "neoruralidade", portanto, pode ser entendida como uma reflexão sobre as formas e a capacidade de adaptação do cenário rural, historicamente vinculado às atividades de cunho familiar, às influências e às exigências externas oriundas da intensa incorporação deste cenário ao circuito da produção capitalista.

No que se refere às políticas públicas para o desenvolvimento rural no Brasil, o que se assistiu, e se assiste, é uma série de medidas, muitas delas paliativas, que insistem no entendimento de que este desenvolvimento só é possível como o aumento da produção agrícola, que linearmente garantiria a geração de empregos e renda no cenário rural.

Neste sentido, as leituras destes textos suscitaram a curiosidade de uma análise mais pontual, objeto deste ensaio, cujo objetivo é tentar discutir alguns poucos elementos que permeiam o embate entre as caracterizações dos cenários considerados urbanos e dos cenários considerados rurais, num caráter mais localizado.

Tal objetivo busca confirmações ou afastamentos empíricos daquilo que é aceito comumente dentro da literatura econômica e busca o entendimento do "quantum" da generalização pode ser representativo quando a análise desce ao nível das economias locais.

No caso deste ensaio, optou-se pela análise de alguns dados socioeconômicos do município de Araguari, Minas Gerais.

A hipótese inicial é a de que uma macro-análise de um determinado movimento socioeconômico pode condicionar e obscurecer análises pontuais, que tendem a muito contribuir para o entendimento das diversidades regionais e, principalmente, locais.

Não existe aqui, em nenhum momento, crítica à metodologia da análise geral, apenas se quer contribuir para o aprofundamento de certas questões, que se 
tornam mais explícitas, quando o cenário de análise é menor, permitindo maior grau de detalhamento.

Entende-se, nessa concepção, que este tipo de análise pode ser um referencial importantíssimo quando se discute o crescimento econômico, com qualidade de vida e preservação ambiental, entendidos como promotores do desenvolvimento sustentável, tornandose, inclusive, elementos contribuintes na elaboração de políticas públicas mais regionalizadas que respeitem as "ruralidades" locais, características de um país continental como o Brasil.

Este ensaio foi dividido em três seções. Na primeira são apresentados alguns aspectos gerais e históricos dos movimentos estabelecidos para o desenvolvimento econômico no Brasil, com destaque para o setor rural e suas dicotomias. Na segunda seção são apresentadas algumas características, históricas e socioeconômicas, regionalizadas do Triângulo Mineiro e localizadas do município de Araguari. Nas considerações finais são indicados alguns elementos de convergências e divergências entre o cenário rural local, Araguari-MG, e as referências bibliográficas citadas nesta introdução.

\section{Aspectos gerais e históricos do desenvolvimento rural no Brasil}

Historicamente, a dicotomia entre campo e cidade é fruto da caracterização de como as atividades de produção são articuladas.

O urbano, fundamentalmente tratado como referencial da modernidade, assumiu o papel de agente promotor do almejado desenvolvimento, via crescimento industrial. 0 rural tratado como sinônimo do arcaico se tornou coadjuvante fornecedor de insumos para a industrialização e de produtos básicos para abastecimento urbano. Assim, tal caracterização permitiu, secularmente, estabelecer o mito da urbanização dinâmico-produtiva e da ruralidade estático-reprodutiva (1).

De maneira geral, o rural brasileiro, até meados do século $X X$, era muito diferente do atual. Nas propriedades rurais, seja nas de "plantation" ou nas de subsistência, produzia-se quase de tudo.

Além das atividades de plantio, na maioria dos casos bastante diversificadas, eram também:

I. criados animais para produção (carne, leite e ovos) e tração;

II. produzidos e adaptados implementos, ferramentas, equipamentos, etc...;

III. confeccionadas roupas para abastecimento da população ocupada;
IV. processados alimentos (embutidos, doces, queijos, etc...).

Atividades de armazenamento e comercialização também estavam incorporadas às "fazendas". Era grande o número de pessoas ocupadas com todas essas atividades e que moravam nas unidades de produção. Grande parte dessas atividades não se destinava à comercialização, e só tinham valor de uso e de operacionalidade interna (GRAZIANO, 1996)

Ao se fazer qualquer referência aos termos agricultura e rural, todas essas atividades estavam inclusas, sendo extremamente abrangentes para todo o setor, incorporando o "antes", o "dentro" e o "após" porteira. Os produtores e as propriedades rurais não eram especializados.

As relações sociais de produção não caracterizavam, na essência capitalista, a estratificação das classes envolvidas nas atividades produtivas. 0 proprietário e 0 produtor eram, fundamentalmente, a mesma pessoa. Mesmo com a fragilidade e o risco de se ter um conceito pronto e acabado, por diversas razões que não cabem em discussão aqui, poder-se-ia afirmar que a prática era de agricultura familiar.

Com o processo de "modernização", via incremento industrial, a agricultura, enquanto atividade diversificada e de subsistência, vai perdendo espaço.

As propriedades rurais passaram a se especializar e a orientar sua produção para o mercado, buscando as chamadas economias de escala, que teoricamente reduziriam os custos de produção, tornando vantajosa a competição para os produtores rurais.

Para Veiga (2001, p. 05), “a corrida tecnológica exigida por essa necessária redução de custos impõe uma especialização das fazendas, que logo torna redundante a maior parte da mão-de-obra não-qualificada".

Tal mudança de perfil pode ser trabalhada em várias frentes de análise:

I. como resultante da necessidade de expansão do mercado de bens de capital para a agricultura;

II. como resposta à demanda de matérias-primas para a indústria;

III. como consequência da necessidade de expansão da pauta de exportação;

IV. como resultado do avanço dos complexos agroindustriais (CAls); ou,

V. como conquista do capital na sua ótica de contínua ocupação de espaços na busca da valorização.

Independente de qual viés se tome para a análise, uma conclusão é sumariamente inquestionável, a de que "as transformações estariam levando novas perspectivas de 
desenvolvimento às áreas rurais". (CARDOSO, 1998, p. 44)

Essas novas perspectivas passam a setorizar, de forma contundente, o que é "antes", o que é "dentro", e o que é "após" a porteira. Atividades anteriormente desenvolvidas por "empregados" rurais foram terceirizadas, eliminando uma série de entraves inclusive jurídicos - ao pleno desenvolvimento capitalista no campo. Até a própria natureza se vê, supostamente, submissa aos ditames do capital.

Entende-se, a partir de orientações de caráter geral, que "... a agricultura se industrializa nesse processo, (...), integrada à grande produção industrial". (GRAZIANO DA SILVA, 1981, p. 44)

Esse novo cenário levou a uma crise da concepção da ruralidade, no mínimo no aspecto economia. Criou-se um espécie de crise de identidade. Há um esvaziamento do referencial teórico urbano vs rural, que "esconde" fenômenos essenciais referentes às formas de produção e reprodução das famílias rurais.

Schneider (2010, p. 08), descreve este movimento assim:

[...] emerge no meio rural uma nova conformação econômica e demográfica que possui como característica fundamental a redução crescente das diferenças entre o urbano e o rural, especialmente no que se refere ao mercado de trabalho, devido ao crescimento da população ocupada em atividades não agrícolas.

Segundo Cardoso (1998, p. 45), "do ponto de vista econômico, com a modernização, os agricultores transformaram-se em mais um elo de uma cadeia produtiva do sistema agroalimentar", sendo que a agricultura, cada vez mais, se tornou uma atividade profissional, incorporando-se ao "agribusiness".
Incorporação que:

I. cresce, pari-passu, ao crescimento do sentido "globalizante" da economia, às rápidas mudanças nas exigências e no estilo de vida dos consumidores;

II. discute a "arquitetura" das plantas na busca de melhor qualidade, e peso, de grãos e animais, com maior "stand" por área trabalhada;

III. racionaliza custos, adotando manejo de pragas, rotação de culturas ou troca de plantel genético;

IV. planeja o escalonamento de plantio, e;

V. exige, sobretudo, a gestão econômicofinanceira da produção.

O resumo de tal mudança de perfil, e consequente influência na concepção da ruralidade são totalmente incorporados nas palavras de Bernard Sorj:

Surge assim um novo padrão agrícola, orientado fundamentalmente para a integração vertical e para o incremento da produção através do aumento da produtividade, embora sem chegar a substituir o antigo padrão de expansão agrícola". (In: GRAZIANO DA SILVA, 1996, p. 23).

Novo padrão agrícola que consiste na generalização de integração da agricultura ao sistema capitalista de produção, via industrialização da agricultura, constituição e expansão dos Complexos Agroindustriais (CAls) e, finalmente, via integração de capitais, conforme a figura 1 .

Figura 1 - Infográfico - Histórico da modernização da agricultura no Brasil

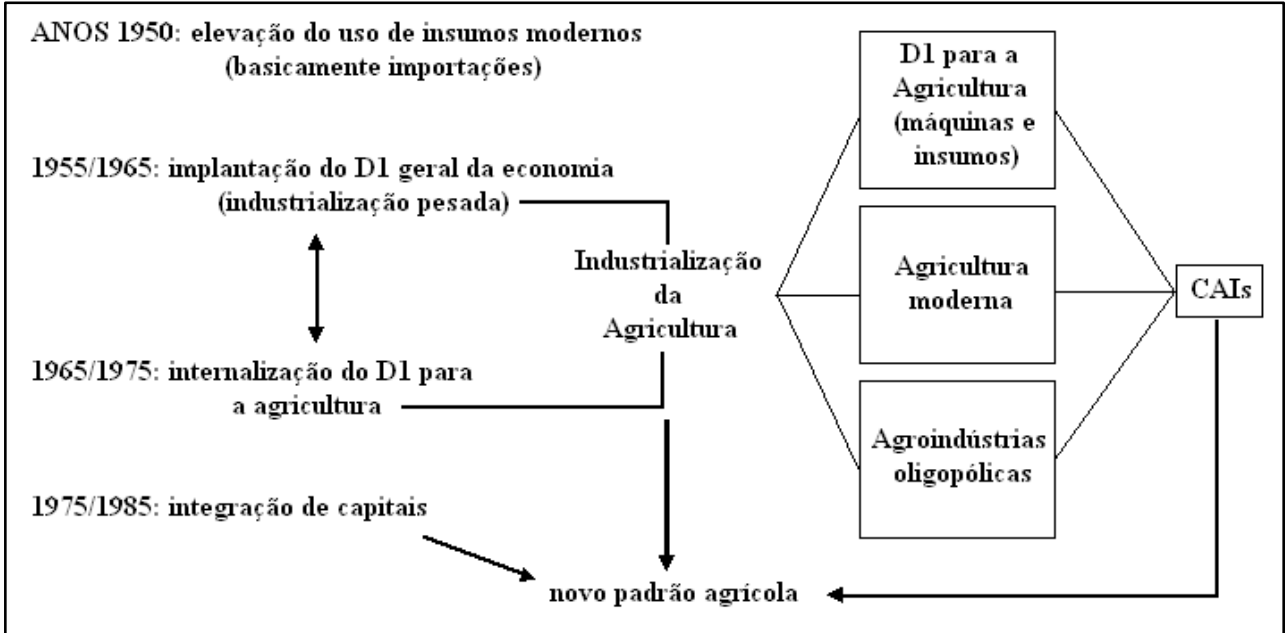

Fonte: GRAZIANO DA SILVA, 1996, p. 30. 
Concluídas estas rápidas considerações acerca da passagem geral da agricultura tradicional para a chamada agricultura moderna, passa-se a um segundo momento de análise que é a investigação numa escala mais regional dos elementos trabalhados, em síntese, neste tópico.

Permanece a caracterização de um cenário capitalista, no qual a essência maior é a valorização do capital, agora alavancado pelo capital financeiro, "com reflexos não apenas na base técnica da atividade agrícola, mas principalmente no plano da concentração e da centralização do capital e da terra". (GRAZIANO DA SILVA, 1996, p. 33)

\section{Aspectos regionais: o Triângulo Mineiro e Araguari-MG}

Segundo vasta literatura econômica, até 1970, o movimento de modernização econômica do Brasil se caracterizou pela crescente concentração da produção industrial no estado de São Paulo, e consequente incorporação da agricultura e do cenário rural deste estado nesse movimento.

Nesse período, o rural paulista, no geral, se mantinha como maior representante do novo padrão de produção agrícola: mecanizado, capitalizado e, voltado para o mercado internacional. Assim permanecia como locomotiva do chamado padrão moderno.

Às outras regiões cabia o papel de fornecedores de produtos destinados ao suprimento da demanda industrial, de mão-de-obra barata e de produtos encarregados de suprir a demanda interna de alimentos.

No caso específico do Triângulo Mineiro, a participação era, fundamentalmente, na produção de grãos para o setor de alimentares e carne bovina.

O entendimento era que a composição dos solos (fracos e ácidos), característica da região de cerrados e o clima inapropriado, representavam obstáculos naturais à prática da agricultura moderna, em grande escala, pois elevariam substancialmente os custos de produção.

A incorporação de outras regiões do Brasil foi capitaneada pela modernização agrícola via "Revolução Verde" (6), auxiliada pelo "boom" dos exportáveis pós Choque do Petróleo de 1973 e, especialmente, pelo crescimento da agroindústria do Complexo Soja, que se tornou o símbolo da modernidade agrícola e do sucesso do agronegócio no Brasil.

Em termos de políticas públicas, à época, merecem destaque, não aprofundando em maiores discussões, a implantação do POLOCENTRO (Programa de Desenvolvimento dos Cerrados) e do PRODECER (Programa de Desenvolvimento dos Cerrados/PROJETO
JICA), cujos objetivos expostos eram tornar o cerrado brasileiro um celeiro capaz de garantir o fornecimento de alimentos a uma parte da população mundial.

No entanto, segundo Pessôa e Inocêncio (2014, p. 08), "a verdadeira razão da escolha do Cerrado como lócus de produção agrícola foi atender ao mercado internacional, pois a soja é uma commodity e favoreceria o desenvolvimento do agronegócio em longo prazo."

Em termos práticos, o que se assistiu foi uma intensa incorporação de território ao circuito da produção agrícola brasileira, com cerca de 70 milhões de hectares, sendo que $50 \%$ destes localizados no Centro-Oeste, com elevada concentração em torno de grandes propriedades voltadas à produção agrícola exportadora. (DELGADO, 1992)

Novamente, há o retorno ao embate entre o moderno e o arcaico, e aspectos de ruralidade, nos aspectos sociais ficam em segundo plano ou a reboque de uma linear e "natural" incorporação aos ditames capital.

Em caráter de conclusão parcial, este ensaio se aporta da análise de Delgado (1992, p. 151), quando cita que "o modelo de integração do Centro-Oeste dedica menos espaço ao pequeno produtor familiar, e se vincula a uma agricultura de 'farmes' capitalizados". (1992:151)

Mesmo que esta consideração de Delgado (1992) se vincule ao Centro-Oeste, é válida também para a região do Triângulo Mineiro, pois, historicamente, é "uma região de passagem" e de interligação entre o CentroSul e o Centro-Oeste brasileiro.

Por sua posição geográfica, a região do Triângulo Mineiro foi impactada de forma intensa pelo avanço da fronteira agrícola nos anos de 1970 e, como fruto ou reflexo da expansão da "modernização" e da fronteira agrícola, há um aumento considerável da participação da região na composição do PIB brasileiro, principalmente pela expansão do chamado "agronegócio". É, assim, um excelente exemplo da incorporação da agricultura ao circuito da produção capitalista, descrita no tópico anterior, neste ensaio.

Atualmente, a região do Triângulo Mineiro é responsável por 13,7\% do PIB de Minas Gerais e 13,8\% do PIB do agronegócio brasileiro (IBGE, 2016), com grande representatividade na produção de café, soja, tomate, carnes bovinas, entre outros produtos, vinculados a este setor, quase a totalidade destinados às exportações.

O Triangulo Mineiro é uma das dez regiões de planejamento de Minas Gerais e engloba um total de 66 municípios, sendo que Araguari é, em ordem decrescente, a quarta em termos de número de habitantes (117.445 hab.) (estimativa IBGE/2017), com $93,4 \%$ caracterizados como habitantes urbanos e 6,6\% caracterizados com rurais. 
Quanto à área geográfica, o município tem uma área de $2.743 \mathrm{~km}^{2}$, com $1.262 \mathrm{~km}^{2}$ (46\%) de área urbana e 1.481 $\mathrm{km}^{2}$ (54\%) de zona rural, nesta com uma densidade de $5,2 \mathrm{hab} . / \mathrm{km} 2$.

A correlação destes dois indicadores caracteriza um cenário extremamente urbanizado, sendo que grande parte da população considerada rural é habitante dos distritos de Amanhece e Piracaíba, além de pequenos aglomerados como Porto dos Barreiros e Ararapira e, são nestas localidades que os aspectos da ruralidade tradicional podem ser mais percebidos: a cooperação, as pequenas práticas agrícolas, alguns aspectos da agricultura iminente familiar, os festejos, etc.

No que se refere à composição do PIB municipal, verifica-se que é um município que se caracteriza pela prestação de serviços, conforme Tabela 1 seguido pelo setor industrial e, por último, pela agropecuária.

Tabela 1 - PIB Municipal - Araguari - MG - \% Por Setores - 2010-2016

\begin{tabular}{ccccc}
\hline ANO & AGROPECUÁRIA & INDÚSTRIA & SERVIÇOS & IMPOSTOS \\
\hline 2010 & $12,26 \%$ & $37,53 \%$ & $42,62 \%$ & $7,60 \%$ \\
2011 & $13,27 \%$ & $34,64 \%$ & $45,01 \%$ & $7,08 \%$ \\
2012 & $11,23 \%$ & $38,07 \%$ & $43,16 \%$ & $7,54 \%$ \\
2013 & $6,45 \%$ & $34,69 \%$ & $50,57 \%$ & $8,29 \%$ \\
2014 & $7,09 \%$ & $35,64 \%$ & $49,13 \%$ & $8,14 \%$ \\
2015 & $5,14 \%$ & $35,32 \%$ & $51,05 \%$ & $8,49 \%$ \\
2016 & $4,42 \%$ & $33,09 \%$ & $53,67 \%$ & $8,81 \%$ \\
\hline
\end{tabular}

Fonte: Adaptado de Fundação João Pinheiro (2014) e IBGE (2016).

Quando se avalia cada setor específico, nota-se a perda da participação da agropecuária na composição do PIB MUNICIPAL, o que pode ser explicado pelo aumento das atividades de transformação de produtos de origem agropecuária que eram comercializados quase na sua totalidade "in natura" e, hoje, em grande parte são processados, recaindo no ambiente setorial da agroindústria.

Araguari-MG é o $9^{\circ}$ município do Brasil, em termos de produção de café (IBGE, 2016), sendo um grande exportador deste produto já beneficiado; é considerada a capital brasileira do tomate (8) e é possui um considerável entreposto de transbordo e esmagamento de soja.

A prática dessas atividades listadas acima e de várias outras, utiliza o que existe de mais moderno em termos de produtos industriais à montante e à jusante da agricultura. $\mathrm{O}$ uso de adubos e fertilizantes químicos, a prática de correção de solo (via fosfatação e calcarização), o manejo de pragas, a utilização de irrigação mecânica, defensivos agrícolas, sementes melhoradas, etc., no caso de culturas e, o uso de inseminação artificial, vacinas, sal mineral, ração animal, etc., no caso da pecuária, movimentam um forte comércio no setor de produtos agropecuários.

Nota-se, portanto, que a modernização agrícola com incorporação do cenário rural pelo capital e as práticas agroindustriais atingiram intensamente o cenário de
Araguari-MG, sendo este mais um excelente exemplo do processo descrito na primeira seção deste ensaio.

No entanto, por mais polêmico que pareça apesar dos percentuais de população urbana serem acima da média brasileira, da baixa densidade demográfica rural, da perda de participação do setor agropecuário na composição do PIB municipal, entre outros aspectos, uma pergunta surge: até que ponto pode-se considerar que o município de Araguari-MG se desruralizou?

Mesmo que os dados acima comprovem o processo de urbanização, pelo pequeno percentual da população rural, uma análise empírica da articulação rural-urbano do município fornece subsídios suficientes para que se possa estabelecer um novo problema de conceito: as cidades incorporadas no circuito da produção capitalista, como Araguari-MG, tornaram-se centros urbanos-ruralizados ou centros rurais-urbanizados?

Acredita-se que a segunda opção é a mais próxima da realidade. Historicamente tais localidades sempre se vincularam ao tradicionalismo rural, que permanece arraigado até os dias atuais.

A propriedade rural ainda é forte componente de "status" social e político, ou seja, o sobrenome da família ainda é elemento de diferenciação social.

O estilo de vida da população, mesmo urbana, guarda o ritmo pacato das sociedades rurais. 
É comum o deslocamento diário de pessoas, tanto proprietários como empregados, às propriedades, mas que mantêm moradia e outras atividades nas cidades.

Como a atividade rural é elemento de "status", é, também, comum a propriedade pertencer a profissionais liberais, comerciantes ou pequenos industriais, que a explora em forma de complementação de renda, lazer, ou como forma de valorização patrimonial.

Ao tomar-se a relação entre população ocupada rural e o número de estabelecimentos, nota-se uma ínfima quantidade de pessoas ocupadas por unidade produtiva, totalmente compatível com as atividades de pequeno e médio porte, frequentes na região, e com as áreas médias das propriedades rurais.

Em resumo, no geral, mesmo que a região faça parte do cenário da modernização agrícola, existem várias especificidades que permitem afirmar um processo parcial de inserção ao mercado moderno.

O tradicionalismo, das relações sociais de convívio e produção, ainda é um elemento marcante.

As mudanças tecnológicas foram absorvidas em partes que interessam à sobrevivência no mercado. A ruptura das relações de produção "arcaicas" não se fez no mesmo padrão da trajetória descrita pelos autores citados na primeira seção deste ensaio.

A agricultura vive uma espécie de compasso lento de espera, atrelando-se aos desígnios de possíveis novas oportunidades de mercado, da instalação de agroindústrias de modifiquem o padrão de produção local ou de uma política macroeconômica que possa permitir uma alteração substancial no seu ritmo de integração nacional e internacional e, assim, a neoruralidade vai se mantendo.

\section{CONSIDERAÇÕES FINAIS}

Por mais que a tendência globalizante da economia force análises de caráter macroeconômico, sugerindo uma intensa propensão à inserção de todas as regiões na aldeia global, cada vez mais se notam dicotomias e necessidades políticas que, na verdade, passam pela avaliação das potencialidades e dos obstáculos regionais e, especialmente, locais.

É esse tipo de avaliação que permite, de maneira segura, a definição do grau de inserção e dos impactos da proposta global sobre as estruturas sócio-econômicas locais.

Segundo Brandão (1996, p 39), "as mudanças tecnológicas e os imperativos da globalização têm colocado novos requisitos localizacionais, reafirmam-se e negam-se externalidades locais e regionais, desconstroem-se regiões".
No caso da macro-análise, parece ocorrer a reafirmação de tais externalidades, com orientação no sentido de que a inserção competitiva só se faz na aceitação passiva das tendências generalizantes da economia, enquanto na escala micro, análises podem negar total ou parcialmente tais externalidades, sugerindo que ainda existem espaços para que a economias locais possam manter seus "equilíbrios" e para que encontrem uma orientação produtiva que melhor absorva sua reais potencialidades.

Em termos da ruralidade, por mais que essa tendência geral seja de destinação ao mercado global, as localidades apresentam, em muitos casos, produtores pluriativos que não caracterizam, na íntegra, a figura do empresário rural.

As atividades, em grande parcela, são mantidas como elementos que podem garantir a própria sobrevivência familiar nas cidades, mantendo um papel importantíssimo no cenário da distribuição de renda e da sustentabilidade.

\section{REFERÊNCIAS}

BRANDÃO, Carlos A. Revisitando a questão das diversidades regionais. Revista Economia Ensaios, Volume 10, ח². Uberlândia, IE/Edufu, 1996.

CARDOSO, Alessandra. Dicotomia rural-urbano, economia local e pluriatividade. Revista Economia Ensaios, Volumes 12/13, nos 2/1. Uberlândia, IE/Edufu, 1998.

DELGADO, Guilherme C. Perspectivas para o desenvolvimento rural brasileiro nos próximos anos. Revista Economia Ensaios, Volumes 6/7, nos 2/1. Uberlândia. IE/Edufu, 1992.

GRAZIANO DA SILVA, J. A nova dinâmica da agricultura brasileira. Campinas: IE/UNICAMP, 1996.

GRAZIANO DA SILVA. O novo rural brasileiro. In: SHIKI, GRAZIANO DA SILVA \& ORTEGA. Agricultura, meio-ambiente e a sustentabilidade do cerrado brasileiro. Uberlândia, UFU/UNICAMP/EMBRAPA, 1997.

GRAZIANO DA SILVA. Progresso técnico e relações de trabalho na agricultura. São Paulo: HUCITEC, 1981.

MEDEIROS, Rosa Maria Vieira. Ruralidades: novos significados para o tradicional rural. In: Dinâmicas do espaço agrário: velhos e novos territórios. Porto Alegre: NEAG, UFRGS, 2017.

MINGIONE, E. \& PUGLIESE, E. A difícil delimitação do "Urbano" e do "Rural": alguns exemplos e implicações teóricas. Revista Crítica de Ciências Sociais, n² 22, 1987.

PESSÔA, Vera Lúcia S.; INOCÊNCIO, Maria Erlan. O PRODECER (re)visitado: as engrenagens da territorialização do capital no Cerrado. CAMPO-TERRITÓRIO: revista de 
geografia agrária. Edição especial do XXI ENGA-2012, p. 122, jun. Uberlândia: IG/UFU, 2014.

SCHNEIDER, Sérgio. Situando o desenvolvimento rural no Brasil: o contexto e as questões em debate. Rev. Econ.

Polit. vol.30 no. 3. São Paulo Jul./Set., 2010.

VEIGA, J. E. da. O Brasil rural precisa de uma estratégia de desenvolvimento. Brasília: Convênio FIPE - IICA

(MDA/CNDRS/NEAD), 2001. 